\title{
Clasificación de las licencias para aplicadores dictadas por el Departamento de Agricultura y Servicios al Consumidor del estado de la Florida (FDACS), relacionadas con agricultura y control de plagas ${ }^{1}$
}

\author{
Frederick M. Fishel y Tatiana Sanchez ${ }^{2}$
}

Esta guía ofrece una explicación de las licencias para aplicadores de pesticidas privados, públicos y comerciales emitidos por FDACS en el Capítulo 487 de los Estatutos de la Florida.

\section{Aplicador privado}

Un aplicador privado, es una persona con licencia para aplicaciones terrestres de pesticidas de uso restringido, con el propósito de producir un producto agrícola en bienes propios o en bienes alquilados por el aplicador o por el empleador del aplicador.

La licencia es apropiada para los dueños y empleados de fincas, ranchos, plantaciones, viveros, jardines, y otros establecimientos que producen productos agrícolas. La licencia es válida para la aplicación de pesticidas de uso restringido para la producción de ornamentales y césped (en un vivero, granja de césped, etc.), pero no para el mantenimiento de plantas ornamentales o césped como por ejemplo, en un campo de golf.

La categoría de aplicador privado para control de plagas agrícolas, es requerida para este tipo de licencia. La categoría aérea no está disponible para aplicadores privados. Una licencia de aplicador comercial puede sustituir a una licencia de aplicador privado en ciertos usos. Para un mayor detalle, consulte la sección de aplicadores comerciales.

\section{Aplicador Público}

Un aplicador público, es un aplicador con licencia empleado por una agencia federal, del estado, del condado, de la ciudad, $u$ otra agencia local o entidad del gobierno que use pesticidas de uso restringido durante el trabajo. Esta licencia es válida para trabajo realizado para una agencia gubernamental, durante la duración del empleo. Para lo siguiente, se debe tener una licencia de aplicador público:

- Los empleados de las compañías eléctricas municipales, de la ciudad y parques del condado, de ferrocarriles de propiedad del gobierno, departamentos viales estatales y federales, y de universidades estatales que usen pesticidas de uso restringido en el trabajo;

- Personal federal y estatal que lleva a cabo la erradicación o control de plagas usando pesticidas de uso restringido, debe tener una licencia de aplicador público, incluyendo la categoría de regulador para el control de plagas.

1. The English version of this document is Agricultural and Related Pest Control Applicator License Classifications under the Florida Department of Agriculture and Consumer Services (FDACS) (PI-13). Este documento es PI-59, uno de una serie del UF/IFAS Extensión. Fecha original de publicación abril de 2005. Repasado abril 2014 Traducido del inglés por Tatiana Sánchez. Visite el sitio web de EDIS en http://edis.ifas.ufl.edu.

2. Frederick M. Fishel, profesor, Departamento de Agronomía y, director de la Oficina de Información de Pesticidas; y Tatiana Sanchez, estudiante licenciado, Doctor en medicina de planta, Extensión UF/IFAS, Gainesville, FL 32611. 
NOTA: Una licencia de aplicador comercial puede sustituir a una licencia de aplicador público si así se desea. Sin embargo, las cuestiones de responsabilidad o riesgo deben ser tomadas en consideración y discutirse con el empleador si un aplicador planea usar una licencia comercial, para realizar aplicaciones de pesticidas como parte del trabajo para una entidad gubernamental.

\section{Aplicador Comercial}

Un aplicador comercial es una persona que utiliza pesticidas de uso restringido en cualquier área agrícola o áreas relacionadas con agricultura con cualquier propósito distinto a los descritos por las otras categorías de las licencias.

Esto incluye los siguientes usos:

- Contratar a alguien para llevar a cabo la aplicación de pesticidas de uso restringido (cuando alguien además del dueño o empleado de la compañía, hace la aplicación).

- Aplicación de pesticidas de uso restringido no hecha por contrato, con fines que no sean la producción agrícola, sin incluir las aplicaciones relacionadas con el trabajo realizadas por empleados del gobierno.

Ejemplos de las licencias requeridas para muchos tipos diferentes de trabajo están dados en la Tabla 1. Algunas de las situaciones que comúnmente ocurren en Florida, en donde una licencia comercial es requerida, incluyen:

- Servicio de aplicación aérea (sin incluir aplicaciones aéreas para salud pública)

- Servicio de control de malezas acuáticas

- Servicio de mantenimiento para cementerios

- Mantenimiento de parques - recreacional (propiedad privada), incluyendo campos atléticos

- Campos de golf - mantenimiento de césped y greens.

- Compañías de químicos o fertilizantes - aplicación personalizada

- Control de plagas en áreas de derecho de vía contratadas por agencias gubernamentales o compañías de servicios públicos

- Compañías de tratamientos de semillas

- Investigación y demostración en campo e invernadero por representantes de la industria

- Investigación y demostración en campo e invernadero por investigadores privados
Un aplicador puede hacer aplicaciones de pesticidas de uso restringido solo en las categorías para las cuales este ha sido licenciado. Por ejemplo, un aplicador de campos de golf debe estar licenciado en la categoría de césped y ornamentales para poder aplicar pesticidas de uso restringido al campo de golf. Si el aplicador aplica pesticidas de uso restringido a un estanque en el campo de golf, él también debe estar licenciado en la categoría acuática.

NOTA: Una licencia de aplicador comercial puede sustituir a una licencia de aplicador privado solo para usos cubiertos por la licencia comercial. Por ejemplo, una licencia comercial con la categoría agrícola para cultivos en hilera, solo podría sustituir en el caso de aplicaciones hechas a cultivos en hilera en bienes de propiedad o bienes alquilados por el aplicador o el empleador del aplicador (pero no sería válida para la aplicación a cultivos de árboles, ornamentales o césped, sitios de bosques, sitios acuáticos, o para tratamiento de animales, tratamiento de semillas, tratamiento de la madera, o fumigación).

\section{Información adicional}

Departamento de Agricultura y Servicios al Consumidor de Florida, División de AES: (850) 617-7851 o http://www. flaes.org. 
Tabla 1. Certificación y requisitos para licencias basados en uso de pesticidas

Uso del Pesticida

AEREO (producción agrícola incluyendo silvicultura, césped, etc.)Bottom of Form

Por dueño de la propiedad o empleado no gubernamental

Por empleado del gobierno (relacionado con el trabajo)

Por servicio contratado

\section{ACUÁTICO}

Por dueño de la propiedad o empleado (producción agrícola solamente)

Por dueño de la propiedad o empleado (cualquier cosa distinta a producción agrícola)

Por empleado del gobierno (producción agrícola o de otro tipo a excepción de salud pública)

\section{COMPANIAS DE QUÍMICOS/FERTILIZANTES}

Por los empleados que hacen demonstraciones o mezcla personalizadas de pesticidas de uso restringido (RUPS)

\section{GRANJA, PLANTACION, RANCHO}

Por dueño de la propiedad o empleado no gubernamental

Por empleado del gobierno (relacionado con el trabajo)

Por servicio contratado

\section{VIVEROS DE HELECHOS}

Por dueño de la propiedad o empleado no gubernamental

Por empleado del gobierno (relacionado con el trabajo)

Por servicio contratado

FUMIGACIÓN (suelo o invernadero )

Por dueño de la propiedad o empleado no gubernamental

Por empleado del gobierno (relacionado con el trabajo)

Por servicio contratado

FUMIGACIÓN (productos agrícolas cosechados crudos)

Por dueño de la propiedad o empleado no gubernamental

Por empleado del gobierno (relacionado con el trabajo)

Por servicio contratado

JARDIN (jardín de su casa)

Por dueño de la propiedad o empleado no gubernamental

Por empleado del gobierno (demostraciones relacionadas con el trabajo, etc.)

Por servicio contratado

\section{CAMPO DE GOLF, PARQUE, CEMENTERIO}

Por dueño de la propiedad o empleado no gubernamental

Por empleado del gobierno (relacionado con el trabajo)

Por servicio contratado

\section{INVERNADERO}

Por dueño de la propiedad o empleado no gubernamental

Por empleado del gobierno (relacionado con el trabajo)

Por servicio contratado
Certificación o Licencia requerida para uso de pesticidas

\begin{tabular}{|l|l|l|}
\hline Privado & Publico & Comercial \\
\hline
\end{tabular}

$\mathrm{X}$

$x$

$X$

$X$

X

X

$x$

X

$x$

$x$

X

$X$

$\mathrm{X}$

$x$

$\mathrm{x}$

$x$

$x$

$x$

$x$

$x$

$x$

X

$x$

X 
Certificación o Licencia requerida para uso de pesticidas

JARDINES INTERIORES Y MANTENIMIENTO DE PLANTAS DE INTERIOR

Por empleado del vivero que provee plantas a otras facilidades pero toma las plantas de la facilidad y las devuelve al vivero o invernaderos para control de plagas

\section{FINCA DE CESPED}

Por propietario o empleado no gubernamental de un vivero, etc.Bottom of Form

Top of Form

Por empleado del gobierno (cama de siembra forestal, etc.)Bottom of Form

Por servicio contratado

INVESTIGACIÓN (parcelas)

Por empleado del gobierno

Cualquier persona que no sea empleado del gobierno incluyendo la industria privada y por contrato de servicio

\section{DERECHO DE VÍA}

Por empleado del gobierno

Por cualquier otra persona, incluyendo servicio por contrato

TRATAMIENTO DE SEMILLAS

Por empleado del gobierno

Por cualquier otra persona:

1. Semilla que vaya a ser usada en la propiedad del titular de la licencia en producción agrícola

2. Semilla para ser vendida o utilizada para cualquier propósito distinto a la producción agrícola en propiedad del titular de la licencia

\section{CONTROL DE RAICES EN EL ALCANTARILLADO}

Por empleado del gobierno

Por cualquier otra persona

\section{MANEJO DE HABITAT PARA VIDA SALVAJE}

Por el propietario o empleado del área de hábitat de vida silvestre (plantación, etc.)

Por empleado del gobierno

Por el contrato de servicio de uno de los dos sujetos descritos anteriormente

\section{TRATAMIENTO DE LA MADERA}

Por empleado del gobierno

Por cualquier otra persona:

1. Madera que se utilizará en la propiedad del titular de la licencia para la producción agrícola

2. Madera que ha de venderse o utilizarse para fines distintos a la producción agrícola en propiedad del titular de la licencia
Publico

Comercial $x$

$X$

$X$

$\mathrm{X}$

$\mathrm{X}$

$X$

$X$ 